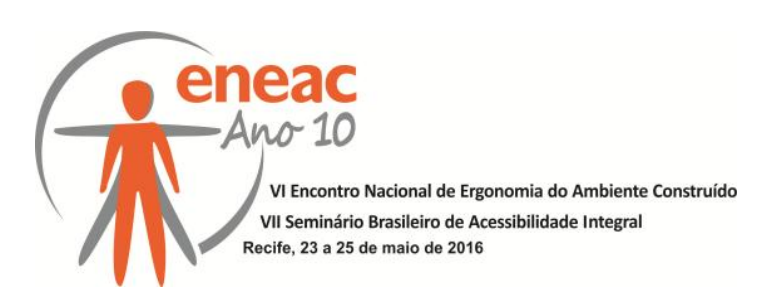

\title{
ESCLEROSE LATERAL AMIOTRÓFICA: UM ESTUDO TEÓRICO SOBRE COZINHAS DOMÉSTICAS VISANDO A PROMOÇÃO DA AUTONOMIA DE PACIENTES
}

\author{
AMORIM, Cíntia Raquel Ferreira (1); \\ BARROS, Bruno Xavier da Silva (2) \\ (1) Universidade Federal de Pernambuco, Especialista \\ e-mail: cintia.r.amorim@gmail.com \\ (2) Universidade Federal de Pernambuco, Mestre \\ e-mail: barros_bruno@hotmail.com
}

\begin{abstract}
RESUMO
A Esclerose Lateral Amiotrófica (ELA) é uma grave patologia neurodegenerativa de causa desconhecida e sem tratamento curativo. Sua principal característica é a perda progressiva da força e atrofia dos músculos do paciente. O ambiente da cozinha é essencialmente um espaço dotado de seções e nichos cuja disposição e sistemas de abertura se configuram como elementos dificultadores da utilização por parte de pacientes portadores de ELA. Dentro deste contexto, visando a promoção da autonomia do paciente, este estudo teórico objetivou a análise da sintomatologia da doença, identificando necessidades e limitações, para, a partir de então, propor recomendações para adaptação de cozinhas.
\end{abstract}

Palavras chave: Esclerose Lateral Amiotrófica (ELA); ambiente construído; cozinha.

\begin{abstract}
The Amyotrophic Lateral Sclerosis (ALS) is a severe neurodegenerative disorder of unknown cause and no curative treatment. Its main feature is the progressive loss of strength and atrophy of the patient's muscles. The kitchen environment is essentially a space with sections and niches whose disposition and opening systems are characterized as difficult in the process of use by people with ALS patients. Within this context, aimed at promoting patient autonomy, this theoretical study aimed to analyze the symptoms of the disease, identifying needs and constraints to propose recommendations for adapting kitchens.
\end{abstract}

Keywords: Amyotrophic Lateral Sclerosis (ALS); built environment; kitchen.

\section{INTRODUÇÃO}

A Esclerose Lateral Amiotrófica (ELA) é uma doença que acomete, de forma crônica, degenerativa e letal, os neurônios motores do sistema nervoso. Suas causas ainda são desconhecidas e sua principal característica é a atrofia progressiva dos músculos do corpo, atingindo membros superiores e inferiores, fala e deglutição (FRANCIS et al., 1999; FESTOFF, 1996; ERICKSON, 1989). 


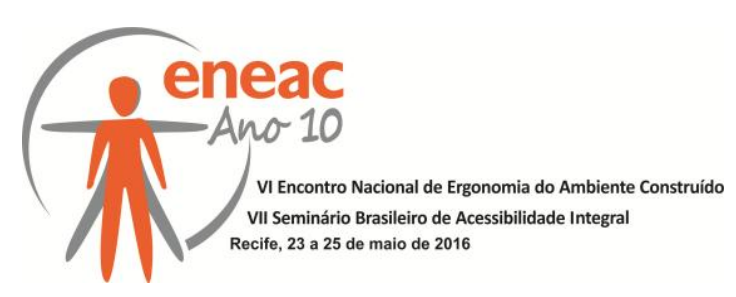

A ELA é responsável por $66 \%$ dos pacientes com doenças do neurônio motor, sendo mais comum nos homens idosos. A média de início dos sintomas é a $5^{\mathbf{a}}$ década de vida, mas a afecção pode se iniciar em qualquer idade no adulto. A sobrevida é de 4 a 5 anos em $50 \%$ dos casos, mas em 15\%, é igual ou superior a 10 anos (BANDEIRA et al, 2010). Entre 5 a $10 \%$ dos casos são herdados de forma autossômica dominante, atingindo, principalmente, pessoas na faixa etária de 40 a 60 anos (BORGES, 2003; FESTOFF, 1996; LIMA, 1979).

Os pacientes com ELA geralmente preservam intacta a sua capacidade intelectual, diferentemente de outros doentes cronicamente acamados em estado vegetativo ou coma. O grau de consciência se mantém íntegro e eles estão perfeitamente conectados ao meio ambiente, vivenciando as dificuldades de uma prisão dentro de si mesmo (CASSEMIRO E ARCE, 2004; BORGES, 2003). A progressão da doença e a gravidade do acometimento muscular interferem na subjetividade, personalidade e modo de compreensão do próprio corpo e seu papel pelo indivíduo, afetando totalmente sua função e participação social até então exercida. Por esta razão, a ELA dificulta a realização de atividades diárias antes exercidas normalmente, modificando totalmente a vida do enfermo. Seu posicionamento frente à sociedade gera sentimentos de desesperança, incapacidade, baixa estima, desespero e medo do desconhecido. (CARVALHO e MENEZES, 2012)

Geralmente, a doença começa pelos membros superiores; eventualmente pelos membros inferiores. Essa dificuldade pode ocorrer quando se tenta abotoar uma roupa, abrir uma lata, amarrar os sapatos, escrever, enfim todas as ações que necessitam de coordenação das mãos (CORREIA, 2016). Com essas limitações, o paciente passa ter desafios diários em sua própria casa. A partir desta realidade, a família e seus vínculos sociais são importantes para facilitar a aceitação do indivíduo com relação à sua enfermidade e às suas limitações. Para Carvalho e Menezes (2012), a família se constitui em um elo de apoio, mas que também apresenta necessidades fundamentais. É necessário que ela consiga se readaptar e reorganizar, para que assim dispense os cuidados necessários ao outro e a si.

O espaço da cozinha sendo de essencial utilização e repleto de acessórios, compartimentos e sistemas de aberturas, pode se revelar como elemento repressor das já limitadas capacidades físicas do paciente. A falta de conformações adequadas dos ambientes construídos para pessoas portadoras da ELA é evidente. Neste sentido a Ergonomia surge como importante aliada no norteamento de adequações dos ambientes e melhoramento da qualidade de vida de pessoas com necessidades específicas, conduzindo à possibilidade de desenvolver ambientes construídos compatíveis com as dificuldades encontradas por esta parcela da sociedade.

Diante desta realidade, este estudo lançou mão de pesquisas bibliográficas e comparativas para atender ao objetivo da análise teórica das características e sintomas da Esclerose Lateral Amiotrófica (ELA) como ponto de partida para a proposição de parâmetros para projeto e adequação do ambiente da cozinha. $O$ estudo se fundamentou nas principais dificuldades enfrentadas por indivíduos acometidos por esta doença. Com esta pesquisa, espera-se propor um norteamento adaptativo do ambiente da cozinha com o intuito de otimizar a qualidade de vida do paciente, promovendo a autonomia no uso do ambiente e redução de sensação de dependência.

\section{FUNDAMENTAÇÃO TEÓRICA}

Esclerose lateral amiotrófica (ELA) é uma das principais doenças neurodegenerativas, ao lado das doenças de Parkinson e de Alzheimer. Pacientes com ELA de início cervical apresentam sintomas nos membros superiores, uni ou bilateralmente. Fraqueza proximal que pode apresentar-se com dificuldade nas tarefas associadas à abdução do ombro e à fraqueza distal que pode se manifestar em atividades que requeiram habilidade de 


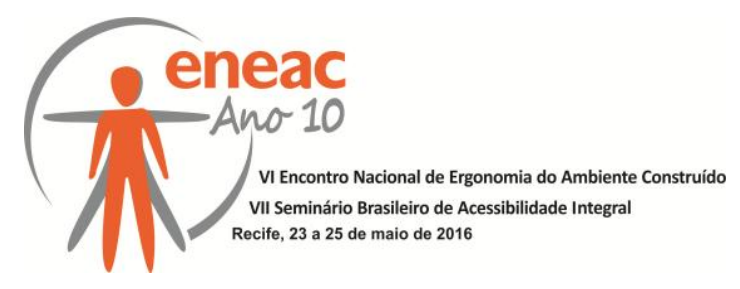

pinçamento. Sinais físicos nos membros superiores podem também ser devidos à disfunção do neurônio motor superior, do inferior ou de ambos. O braço pode apresentar atrofia intensa com fasciculação profusa, mas com reflexos hiperativos (PROTOCOLO CLÍNICO E DIRETRIZES TERAPEUUTICAS, 2009; FRANCIS et al., 1999; FESTOFF, 1996; ERICKSON, 1989).

Nesta fase inicial da doença são sintomas específicos, as alterações e o enfraquecimento muscular (caracterizados inicialmente nos membros superiores); a perda de equilíbrio; o aparecimento de cãibras musculares constantes e que demoram a passar; a dificuldade para usar uma das mãos; a dificuldade para subir e descer escadas e o cansaço sem motivo aparente (LIMA e GOMES, 2010; NELSON, 2000; CORREIA, 2016).

Com a doença, inicialmente ocorre apenas uma diminuição da habilidade para realizar movimentos muito delicados e precisos, com o tempo, surge a diminuição da velocidade dos movimentos. Na medida em que a fraqueza muscular progride, não é mais possível realizar alguns tipos de movimentos que dependem dos músculos afetados. Nesses casos, o paciente frequentemente se adapta para compensar as dificuldades: pode realizar os movimentos de forma mais lenta, pode adotar outras posições ou utilizar outros músculos para realizar os movimentos mais comprometidos (ANEQUINI et al 2006; ZINNI et al, 2004).

Com a evolução da doença, as mãos adquirem forma do tipo cadavérica, devido à atrofia muscular. Os sintomas passam das mãos e se expandem para os antebraços, braços e cintura escapular. Os membros inferiores começam a ter comprometimento muscular depois que os membros superiores já estiverem acometidos. A marcha tende a sofrer alterações devido ao início do comprometimento atrófico muscular, como o pé caído. A debilidade muscular também se expressa nos músculos da faringe, laringe e língua onde a deglutição e a fala estarão comprometidas. A sensibilidade em geral não está afetada, as parestesias (sensações cutâneas como formigamento e queimação) são raras e quando presentes são decorrentes de compressões nervosas posturais. As cãibras estão presentes e acontecem devido à desnervação muscular (ZINNI et al, 2004; JUNIOR, 2013).

Embora o paciente esteja sujeito a esta série de sintomas, o raciocínio intelectual, a visão, a audição, o paladar, o olfato e o tato não são alterados. Os reflexos ora estão exaltados, ora diminuídos, dependendo da relação entre o comprometimento do primeiro e do segundo neurônio. Na maioria dos casos, a esclerose lateral amiotrófica não afeta as funções sexual, intestinal e vesical (ABRELA, 2007; MARTINI et al, 2009, CASSEMIRO E ARCE, 2004; BORGES, 2003).

Os pacientes portadores de ELA apresentam uma evolução muito variável tanto no que tange aos músculos acometidos como a velocidade do comprometimento. Nota-se uma adaptação motora para as funções comprometidas, sugerindo que o cérebro tem a capacidade de adaptar-se, utilizando-se de outros padrões de inervação para que a função se preserve (ZINNI et al, 2004; COSTA et al). Para Zinni et al. (2004), aproveitando a capacidade de readaptação do cérebro, as medidas de reabilitação são fundamentais para a qualidade de vida do paciente. Acrescente-se a essa condição, que pode ser devido à magnífica propriedade da plasticidade cerebral, o fato de não haver comprometimento das funções intelectuais e, portanto, o paciente ter condições de ser produtivo e aproveitar ao máximo suas capacidades criativas e profissionais.

A evolução da doença também ocasiona espasticidade, que leva à rigidez muscular e ao aumento dos reflexos musculares. A espasticidade corresponde a um aumento da atividade reflexa dos músculos que perderam o controle exercido pelos neurônios motores superiores (DURÁN, 2006; TEIVE et al, 1998). Com isso pode-se ocasionar a perda do equilíbrio, tropeções e escorregões que são causas comuns de queda e podem resultar em contusões, fraturas, lacerações ou traumas cranianos. Embora muitas quedas não resultem em nenhum dano físico, cair, ainda que uma vez, pode resultar em um medo intenso de participar de 


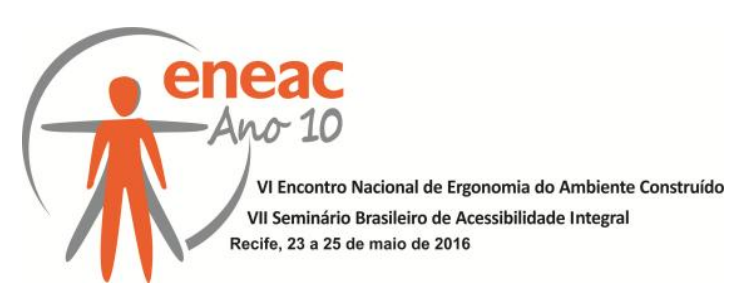

quaisquer atividades, incluindo sair de casa. Embora nem todas as quedas possam ser prevenidas, existem muitos modos de eliminar os incidentes, seja para manter o equilíbrio ou para evitar tropeções (ANEQUINI et al. 2006).

Devido ao quadro de evolução e consequente perda de funcionalidade muscular, são recomendados recursos auxiliares para a reabilitação e melhora das atividades de vida diária. De acordo com Durán (2006), a prescrição de órteses e equipamentos como: tornozeleira antiequino, talas, andadores, bengalas e muletas podem ser indicadas como estratégias para otimizar a deambulação. É indicado colar cervical macio para a fase inicial de fraqueza muscular de pescoço e, posteriormente, o semirrígido para os casos de "drop head". Segundo a autora, a indicação de cadeira de roda adaptada é prescrita em uma fase anterior à perda de marcha, como um recurso de conservação de energia e melhoria da qualidade de vida do paciente.

Embora não haja consenso sobre o conceito de qualidade de vida, um grupo de especialistas da Organização Mundial da Saúde, de diferentes culturas, pôde entender que a qualidade de vida inclui ao menos três dimensões: a física, a psicológica e a social (KLUTHCOVSKY e TAKAYANAGUI, 2007). A questão sobre qualidade de vida vem assumindo importância sob vários aspectos nos últimos anos, particularmente no que diz respeito a sua avaliação ou mensuração. Este fator torna-se ainda mais importante em doenças degenerativas como a ELA, em que a mensuração da eficácia do tratamento se traduz na qualidade de vida dos anos vividos diante da ausência de cura (MELLO et al, 2009).

Dentro deste contexto, surge a necessidade de buscar a adequação de artefatos e entorno às necessidades dos pacientes como forma de melhoria da qualidade de vida destes. A Ergonomia é uma disciplina orientada para uma abordagem sistêmica de todos os aspectos da atividade humana, oferecendo uma abordagem ampla em seu campo de ação. Desta forma, esta área de conhecimento se revela como de suma importância para orientar projetos que possam auxiliar o bem estar das pessoas doentes em seus lares. Para Martins et al. (2001) por meio da integração entre acessibilidade, antropometria, design ergonômico, design universal, ergonomia e usabilidade, é possível empregar soluções mais condizentes com as reais necessidades dos usuários, permitindo contemplar diversas potencialidades, que não seriam adequadamente atendidas pela ótica de uma única área do conhecimento.

O olhar ergonômico, quando lançado sobre ambientes domésticos, pode envolver diversas interações entre os usuários e cada um dos espaços projetados. Cada ambiente residencial apresenta seus próprios artefatos e, consequentemente, atividades distintas são realizadas. Para Ricardo et al. (2005), a cozinha é considerada um centro de grande importância na vida familiar, pode ser direta e/ou indiretamente um influenciador da atmosfera de felicidade de toda família. Os autores afirmam que uma cozinha bem planejada faz com que os membros da família, se aproximem da pessoa que ali trabalha, e se interaja nas atividades com ela, reduzindo o distanciamento entre os mesmos.

Para Mauro (1989), o desempenho de uma atividade, ou um ambiente inadequado, oferece ao ser humano uma série de riscos físicos e psicológicos à sua saúde. Sedo assim, é de suma importância que o ambiente da cozinha, seja bem planejado para que a atividade seja produtiva, com menor custo físico, garantindo mais saúde e produtividade. A cozinha é um ambiente caracterizado por diversos perigos iminentes, os quais exigem uma atenção e capacidade física para manuseio, alcances e uso de força em atividades manuais em geral. As perdas de capacidades musculares gradativas em pessoas com ELA evidenciam a necessidade de uma cozinha compatível com suas limitações. A aplicação da ergonomia no ambiente de trabalho cozinha residencial faz se cada vez mais necessária como forma de aumentar a qualidade de vida das pessoas que dela se utilizam. (RICARDO et al. 2005). 


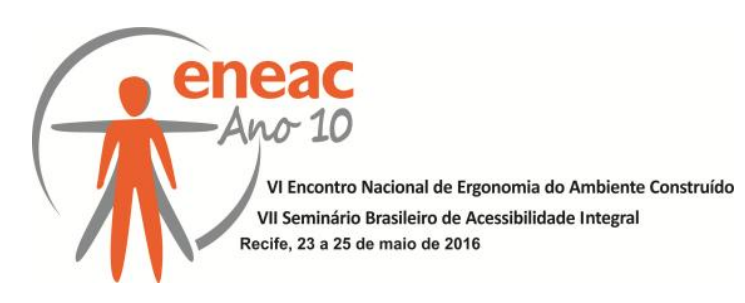

Com o natural processo evolutivo das edificações, a preocupação estética e de modernidade passou a ser prioridade, em detrimento a funcionalidade. As cozinhas atuais e modernas tendem a ter muitos compartimentos, divisões pequenas para cada elemento. Eletros embutidos. Armários basculantes de grandes extensões. Materiais com alto brilho, como vidro e espelho. Cozinhas americanas e com pequenos espaços. Bancadas integradas que exigem acentos de banquetas (KNOPIK, 2015).

A ausência de força muscular em pacientes com ELA pode prejudicar o manuseio de utensílios e ferramentas; comprometer a abertura de compartimentos e a dinâmica de realização das atividades que exigem movimentação, pega e exercícios de fixação e força sobre objetos. Essas dificuldades podem ser mais evidentes quando o usuário acometido pela doença faz uso de uma cozinha não adaptada.

Para otimizar a usabilidade da habitação deve-se compreender as relações de uso nos ambientes em que se realizam as atividades. Ou seja, as características físicas e funcionais do ambiente, dos móveis e dos objetos, bem como as características físicas e emocionais dos usuários (PEZZINI, 2009). Sendo assim, faz-se necessário o estudo detalhado da sintomatologia da Esclerose Lateral Amiotrófica como passo inicial de um processo de norteamento da adaptação do ambiente da cozinha aos indivíduos com esta doença.

\section{METODOLOGIA}

Para a construção desta pesquisa, a metodologia utilizada foi a Pesquisa Bibliográfica, onde, por meio de uma revisão da literatura, buscaram-se insumos teóricos suficientes para o conhecimento do atual estado das pesquisas relacionas à Esclerose Lateral Amiotrófica. Através da literatura encontramos sintomas que delimitam as dificuldades e necessidades enfrentadas por pacientes em seu cotidiano, bem como orientações para que haja qualidade de vida nos anos subsequentes de sua vida após o diagnóstico da doença. A pesquisa bibliográfica também forneceu embasamento teórico para a construção de propostas ergonômicas de otimização das condições de desempenho da atividade no ambiente construído da cozinha. Neste sentido, alimentamo-nos do argumento de Gil (2008), o qual enfatiza que a pesquisa bibliográfica possibilita um amplo alcance de informações, além de permitir a utilização de dados dispersos em inúmeras publicações, auxiliando também na construção, ou na melhor definição do quadro conceitual que envolve o objeto de estudo proposto.

Outro método que, ao longo da pesquisa, se mostrou necessário foi o Comparativo, o qual se lançou mão para evidenciar as discrepâncias entre ambientes "comuns" e ambientes que possibilitariam a adequação das necessidades de pacientes com ELA. Para Lakatos e Marconi (2011) o método comparativo realiza comparações com a finalidade de verificar semelhanças e explicar divergências. Neste sentido, o método nos auxiliou no sentido de prever riscos e situações inadequadas, as quais poderiam impedir o desenvolvimento de atividades. Sendo assim, vimos que o método comparativo procede pela investigação de indivíduos, classes, fenômenos ou fatos, com vistas a ressaltar as diferenças e similaridades entre eles (GIL, 2008).

\section{RESULTADOS}

A cozinha considerada como ambiente não só para alimentação, mas também para o contato social, pode ser uma saída para integrar o doente com a família e permitir que ele possa ter momentos de satisfação. Para promover sua motivação em se alimentar, assim 


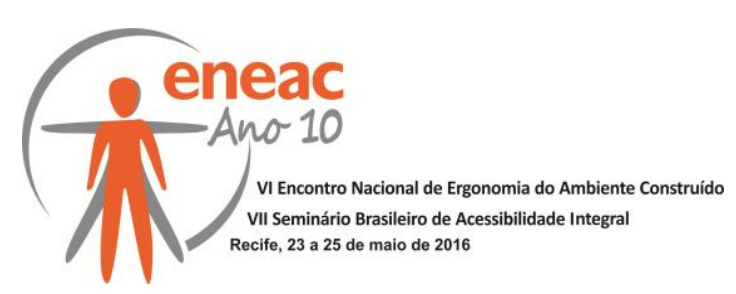

como para ter uma oportunidade de integrar-se em um convívio diário, faz-se necessário que esta cozinha apresente requisitos de adaptação direcionada a este tipo de paciente.

Para atender as necessidades dos portadores da ELA, foram considerados fatores que não estão presentes nos projetos de ambiente construído de cozinhas comuns, muitas vezes voltados apenas para a satisfação estética e com pouca ou nenhuma adaptabilidade. Foram considerados direcionamentos que possam auxiliar na adequação dos espaços às pessoas portadoras da doença, oferecendo usabilidade e auxílio na qualidade de vida. Para uma maior organização dos dados, as diretrizes propostas foram subdivididas entre requisitos de Mobiliário; Eletrodomésticos; Espaços de Circulação; lluminação; e Recomendações de Segurança, os quais podem ser acompanhados a seguir:

\section{a) MOBILIÁRIO}

1 - Deve-se optar por sistemas de aberturas facilitados, com uso de portas de correr que não demandem esforço muscular. Sistemas de correr auxiliados por trilhos para sustentação e com travas de fechamento para que as portas não escorreguem. No caso de gavetas, deve-se optar por sistemas de trava e abertura através de toque;

2 - Os elementos de acionamento para abertura de portas devem possuir formato de fácil pega, não exigindo firmeza, precisão ou torção do punho para seu acionamento. (ABNTNBR 9050:2015);

3 - As corrediças e dobradiças dos móveis devem possuir amortecedores (para evitar impactos), já que a força do indivíduo é perdida gradualmente e o paciente passa por momentos de não percepção da força exercida;

4 - Recomenda-se o emprego de puxadores embutidos, pois evitam batidas de corpo e enrosco de roupas. Além disto, são confortáveis para qualquer dimensão de mãos.

5 - Os assentos devem ser confortáveis, de fácil acesso e de apoio seguro e estável (um mínimo de quatro pontos de apoio no piso), evitando possíveis quedas, dificuldade de sentar-se e insegurança. Devem possuir encosto e estar dentro das normas de altura do assento entre 50 a $60 \mathrm{~cm}$. Deste modo, devem ser evitadas as banquetas e assentos tubulares ou de estrutura instável;

6 - Sempre que possível, deve-se optar pelo uso de prateleiras ou nichos, pois facilitam o acesso ao uso uma vez que suprimem uma porta ou gaveta;

7 - Devem-se proporcionar placas de sinalização nas portas de cada nicho fechado, onde devem ser descritos quais artefatos encontram naquele compartimento, esta atitude evita o excesso de deambulação no ambiente à procura de material;

8 - Com o avanço da doença, os pacientes vêm a lançar mão de cadeiras de rodas, neste caso, devem-se adequar as dimensões de acesso considerando a altura de um cadeirante (normatizados pela NBR 9050:2015), não esquecendo os requisitos adicionais de pegas e aberturas relacionados ao baixo tônus muscular;

9 - Parte do tampo de balcões deve ser fixada à altura de acesso por indivíduos cadeirantes, deste modo, o balcão pode ser utilizado por pacientes sentados em cadeiras ou pelos próprios pacientes cadeirantes;

10 - Deve-se optar pela disposição de torneira tipo alavanca ou com sensores, pois evita a necessidade de torque ou torção, facilitando o uso por pessoas com baixo tônus muscular; 


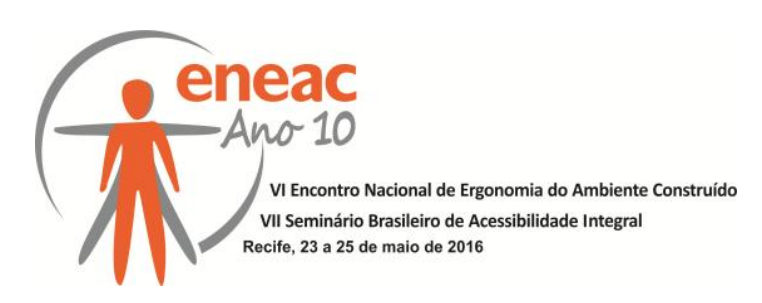

b) ELETRODOMÉSTICOS

11 - É importante que os eletros estejam armazenados ao alcance do paciente e no local exato de seu uso, evitando que o indivíduo doente tenha que conduzir a carga do artefato até o local de elaboração do alimento;

c) ESPAÇOS DE CIRCULAÇÃO

12 - Devem-se proporcionar acessos livres para boa orientação espacial tanto por pacientes cadeirantes, quanto por muletantes ou usuários de andador.

d) ILUMINAÇÃO

13 - As cozinhas deverão conter um sistema duplo de iluminação, a iluminação geral e iluminação direcionada, para os planos de trabalho. Deste modo, se propicia o fácil acesso e direcionamento correto na busca de objetos e materiais, iluminando o geral e cada compartimento.

\section{e) RECOMENDAÇÕES DE SEGURANÇA}

14 - Fixação de barras de apoio nas paredes e/ou móveis para possível necessidade de amparo e auxílio na deambulação.

15 - Colocação de tampos dos dois lados do fogão possibilita o apoio de panelas e objetos quentes em casos de emergência;

16 - Previsão de instalação de detector de fumaça e gás, oferecendo maior segurança para pessoas com acuidade olfativa reduzida;

17 - Na cozinha os cantos dos tampos devem ter faixa de outra cor para contraste visual, reduzindo o risco de choques e colisões;

18 - A verticalização de armários deve ser evitada, pois pode impossibilitar determinadas tarefas ou, ainda, causar acidentes (caso o paciente venha fazer uso de escadas ou bancos);

19 - Devem-se evitar prateleiras, portas e gavetas em vidro, para reduzir o nível de risco do acidente em caso de queda do paciente;

20 - Os armários devem ter espaço para entrada dos pés e (no caso de pacientes cadeirantes) acesso à aproximação de cadeira de rodas;

21 - O uso de sistemas de travas nos gaveteiros também oferece segurança, permitindo que as gavetas abram completamente, sem caírem;

22 - Na composição do ambiente devem ser utilizados pisos antiderrapantes, aumentando a estabilidade do paciente e evitando quedas por falta de atrito.

A literatura oferece subsídios teóricos para a compreensão de diversas necessidades básicas do indivíduo com ELA, as quais podem ser convertidas em especificações para a composição do ambiente da cozinha adaptada a estes pacientes. No entanto, é natural que requisitos mais específicos de direcionamento surjam apenas em decorrência das necessidades individuais de cada paciente, assim como sugestões apontadas pela família. 


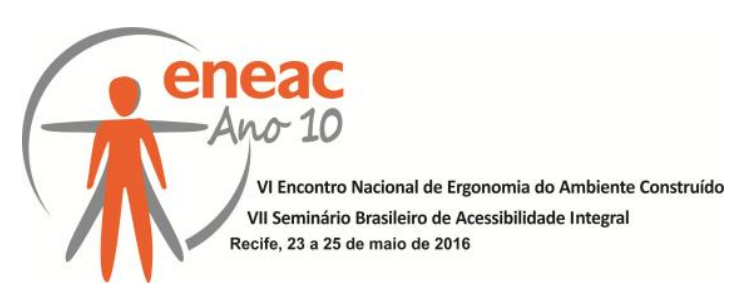

\section{CONCLUSÕES}

Reforçado pelo fato de que as condições de consciência dos pacientes com Esclerose Lateral Amiotrófica não são afetadas, estes necessitam ainda mais de uma integração social e fortalecimento da autoestima, para que possam ter uma melhor qualidade de vida após 0 aparecimento dos sintomas da doença. Dessa maneira, condições que diminuam a sensação de inutilidade e dependência podem ampliar consideravelmente o seu bem estar e sua estima. Uma vez que a ELA ainda não tem cura, a qualidade de vida dos pacientes torna-se fator fundamental na experiência vivida pelos mesmos e pela família, deste modo, as condições de independência e convívio social proporcionado pelo ambiente (por meio de adequações) são um fator de preservação da saúde física e mental destes indivíduos.

A elaboração de cozinhas na atualidade está relacionada a uma significativa evidenciação dos apelos estéticos, são prioritárias as questões de modernização que não consideram os aspectos ergonômicos. Devido a esta realidade, ampliam-se os riscos de acidentes que indivíduos portadores de ELA podem vir a sofrer no ambiente cozinha, os quais são agravados pela debilidade causada pelo progresso da doença. O paciente portador da ELA possui uma série de necessidades e cuidados específicos, os quais determinam advertências no projeto de cozinhas. A ausência de adaptações e a má adequação do ambiente podem causar sérios acidentes, ou até mesmo a debilidade da autoestima, a qual pode ocorrer devido à dificuldade de interação com o ambiente residencial e impossibilidade de realização de tarefas antes consideradas simples pelo paciente.

A pesquisa nos permitiu enxergar a necessidade de maiores investigações na área, fornecendo assim subsídios para novos estudos, no sentido de se buscar outras formas de auxiliar esta parcela da sociedade. Neste ponto, o olhar da Ergonomia atua como elemento fundamental no estabelecimento de determinações que auxiliem os pacientes. Os princípios da Ergonomia do Ambiente Construído surgem como norteadores significativamente importantes para o desenvolvimento de projetos que possam adaptar ambientes à realidade dos enfermos. Neste sentido, a proposição de diretrizes de projeto e reforma de cozinhas domésticas de uso permissível às pessoas com ELA se revelou extremamente importante na melhoria da qualidade de vida destes indivíduos. $O$ atendimento aos aspectos propostos vem a permitir uma maior autonomia destes indivíduos neste ambiente, permitindo não só a elaboração de alimentos, como também sua interação com a família (além da evidente melhoria na autoestima).

As diretrizes estabelecidas nesta pesquisa vêm a servir como referência para arquitetos, designers e projetistas em futuros projetos de reforma ou concepção de cozinhas adaptadas. Tais diretrizes foram alicerçadas em pesquisas teóricas, o primeiro passo para a busca por um norteamento formal, no entanto, recomendamos que novas pesquisas sejam realizadas investigando o comportamento de pacientes, identificando novas necessidades e testando/incrementando as diretrizes propostas. Também indicamos a realização de estudos voltados para Ergonomia e Acessibilidade direcionados às necessidades especiais de pessoas acometidas por doenças neurodegenerativas, as quais não são contempladas de forma específica na norma NBR 9050:2015. Os estudos devem buscar a composição de requisitos que possibilitem a configuração e adaptação de ambientes para utilização deste tipo de paciente.

Com o resultado da investigação sugere-se ainda que outros ambientes também sejam alvos de pesquisas, tais como quartos e banheiros, para que haja possíveis soluções na adaptação das residências às condições dos doentes, para lhes proporcionar uma situação de convivência melhor em seus anos de vida subsequentes ao diagnóstico da doença. 


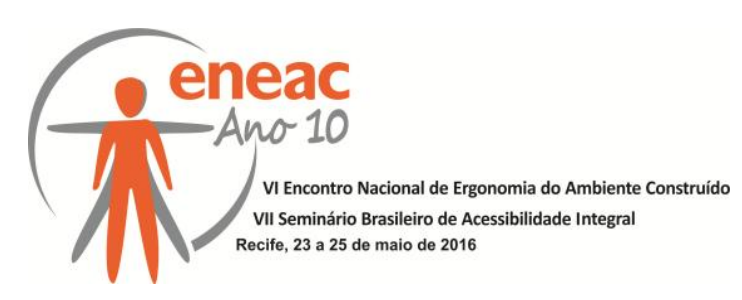

\section{REFERÊNCIAS BIBLIOGRÁFICAS}

ABRELA - ASSOCIAÇÃO BRASILEIRA DE ESCLEROSE LATERAL AMIOTRÓFICA. Tudo sobre ela. Disponível em < https://www.tudosobreela.com.br/relacoes/dozepass.shtml> Acesso: 08/02/2016.

ANEQUINI,Isabela P; PALLESI, Juliana B; FERNANDES, Élica; FÁVERO, Francis M;FONTES, Sissy V; QUADROS, Abrahão AJ; SILVA, Helga CA; OLIVEIRA, Acary SB. Avaliação das atividades da ABRELA: Orientações oferecidas, expectativas atingidas?. Anais do V Simpósio Brasileiro de DNM/ELA "Esclerose Lateral Amiotrófica: sua manifestação no Brasil,2006. Disponívelem<

http://www.hsp.epm.br/dneuro/neurociencias/neurociencias_v14_02_suplemento.pdf\#page= 65> Acesso: 09/02/2016.

COSTA, Fabrícia A.; MARTINS ,Liziane J.N.S.; SILVA, Nathália P.O. Esclerose Lateral Amiotrófica e a Fisioterapia Motora. Disponível em: < http://www.ipg.org.br/ipg/project/ipg/public/uploads/site/downloads/7df03136dec0f63e5b2be9 f29600b549.pdf>Acesso: 10/02/2016.

DURÁN, Martina A. Fisioterapia Motora na Esclerose Lateral Amiotrófica. Anais do V Simpósio Brasileiro de DNM/ELA "Esclerose Lateral Amiotrófica: sua manifestação no Brasil, 2006.Disponível em<

http://www.hsp.epm.br/dneuro/neurociencias/neurociencias_v14_02_suplemento.pdf\#page= 65> Acesso: 03/02/2016.

BANDEIRA, Marinho Fabrício; QUADROS, Nadja Nara Camacam de Lima; ALMEIDA, Karlo Jozefo Quadros de; CALDEIRA, Rafaela de Morais. Avaliação da qualidade de vida de pacientes portadores de Esclerose Lateral Amiotrófica (ELA) em Brasília. Rev Neurocienc, 2010;18(2):133-138.

BERNARDO, D. C. R; NASCIMENTO, J.P. B; SILVEIRA, P. R ; SOARES, K. G. R. O estudo da ergonomia e seus benefícios no ambiente de trabalho: uma pesquisa bibliográfica. Saberes Interdisciplinares, v. VI, p. 95-109, 2012.

BORGES, Claudia Fernanda. Dependência e morte da "mãe de família": a solidariedade familiar e comunitária nos cuidados com a paciente de esclerose lateral amiotrófica. Psicologia em Estudo, Maringá, v. 8, num. esp., p. 21-29, 2003.

CARVALHO LC de, MENEZES TMO. Sistematização da assistência de enfermagem a um cliente com Esclerose Lateral Amiotrófica: Estudo de Caso. Journal of Nursing, revista de enfermagem, UFPE online, 2012.

CORREIA, MC. Esclerose Lateral Amiotrófica. Disponível em: <http://www.mccorreia.com/cerebro/esclelateral.htm> Acesso: 06/02/2016.

CASSEMIRO, C. R., ARCE, C. G. Comunicação visual por computador na esclerose lateral amiotrófica. Arq Bras Oftalmol, 2004;67:295-300.

DURÁN, M. A. Fisioterapia Motora na Esclerose Lateral Amiotrófica. Revista Neurociências V14 N2 (supl-versão eletrônica) -abr/jun, 2006.

ERICKSON, R. P.; LIE, M. R. Wineinger MA. Rehabilitation in multiple sclerosis. Mayo Clin Proc 1989;64:818-28.

FRANCIS, K.; BACH, J.R.; DELISA, J.A. Evaluation and rehabilitation of patients with adult motor neuron disease. Arch Phys Med Rehabil 1999;80:951-63.

FESTOFF, B. W. Amyotrophic lateral sclerosis: current and future treatment strategies [published in erratum Drugs 1996;51:28-44]. Drugs 1996;51:28-44. 


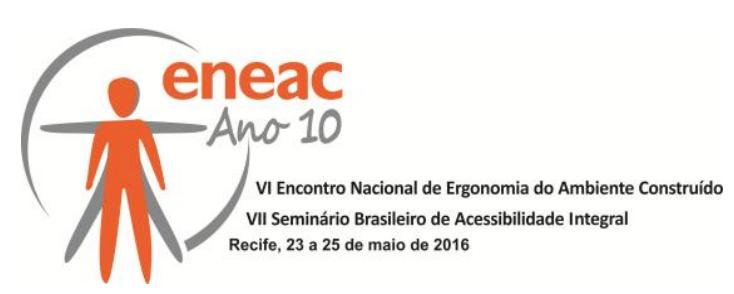

GIL, A. C. Métodos e técnicas de pesquisa social. $6^{\circ}$ Ed, São Paulo: Atlas, 2008.

JUNIOR, Eduardo Linden. Abordagem Fisioterapêutica na Esclerose Lateral

Amiotrófica: Artigo de Atualização. Rev Neurocienc, Taquara, p. 313-318, 2013.

KNOPIK, Fernanda. Tendências das Cozinhas Modernas. Arquidicas. Revista on-line.

Disponível em<http://www.arquidicas.com.br/cozinhas-modernas/> Acesso: 10/02/2016.

KLUTHCOVSKY, Ana Cláudia G. C.; TAKAYANAGUI, Angela M. M. Qualidade de vida aspectos conceituais. Revista Salus. Guarapuava, 2007; 1(1): 13-15. Disponível em< http://www.observatorionacionaldoidoso.fiocruz.br/biblioteca/_artigos/12.pdf> 10/02/2016.

LAKATOS, E. M. \& MARCONI, M.A. Metodologia Científica. 6Ed. São Paulo: Atlas, 2011.

LIMA, J. M.B. de. Contribuição para o estudo da esclerose lateral amiotrófica: aspectos clínicos,epidemiológicos e virológicos. Dissertação de Mestrado, Universidade Federal do Rio de Janeiro, Rio de Janeiro, 1979.

LIMA, S. R.; GOMES, K. B. Esclerose lateral amiotrófica e o tratamento com células-tronco. Rev Bras Clin Med. São Paulo, 2010 nov-dez;8(6):531-7.

MARTINI, de Frederic H.; TALLITSCH Robert B.; TIMMONS, Michael J. Anatomia do corpo humano. 6를 Ed. Porto alegre: Artmed, , 2009.

MAURO, M.Y.C. Ensino da ergonomia em enfermagem. Anais do 4ํㅗㄴ Seminário Brasileiro de ergonomia. Rio de Janeiro, 1989. 488p.

MARTINS, L.B. et al. Sistema de informação e Design univeral - Garantia de Acessibilidade. In Seminário Acessibiliad, Tecnologia da informação e inclusão digital, 1., São Paulo. Anais eletrônicos do I Seminário Acessibilidade, Tecnologia da Informação e Inclusão Digital. São Paulo: USP, 2001. Disponível em <http://www.fsp.usp.br/acessibilidade> Acesso: 04/02/2016.

MELLO, Mariana Pimentel de. ORSINI, Marco. NASCIMENTO, Osvaldo JM. PERNES. Marli. LIMA, José Mauro Braz de. HEITOR, Cláudio. LEITE, Marco Antonio Araújo. O paciente oculto: Qualidade de Vida entre cuidadores e pacientes com diagnóstico de Esclerose Lateral Amiotrófica. Rev Bras Neurol, 45 (4): 5-16, 2009.

NELSON, L. M.; MATKIN, C.; LONGSTRETH, W. T.; MCGUIRE, V. Population - based case - control study of amyotrophic lateral sclerosis in Western Washington State. II.diet. Am J Epidemiol 2000;151(2): 164-173.

PROTOCOLO CLÍNICO DE DIRETRIZES TERAPEUTICAS. Esclerose Lateral Amiotrófica. Portaria SAS/MS no 496, de 23 de dezembro de 2009. Disponível em< http://neurologiahu.ufsc.br/files/2012/12/PCDT_MS_2009_Esclerose-Lateral-

Amiotr\%C3\%B3fica.pdf> Acesso em: 10/02/2016.

RICARDO, Lídia Nara. MACEDO, Ingrid da Silva. CASTRO, Gisele Dias de. MAFRA, Simone Caldas Tavares. Análise da segurança do trabalho no âmbito domiciliar a partir da ergonomia: uma avaliação do espaço cozinha. II Workshop de Análise Ergonômica do Trabalho na UFV, Viçosa, Minas Gerais, 2005.

TEIVE, Hélio A.G; ZONTA, Marise; KUMAGAI, Yumi. Tratamento da espasticidade: uma atualização. Arq. Neuro-Psiquiatr. vol.56 n.4 São Paulo Dec. 1998 Disponível em < http://www.scielo.br/scielo.php?script=sci_arttext\&pid=S0004-282X1998000500025>

Acesso: 05/02/2016.

PEZZINI, Marina Ramos. Usabilidade de armários modulados em apartamentos reduzidos. Dissertação (Mestrado) - UFSC, Santa Catarina, 2009. Acesso em: 07/02/2016. 


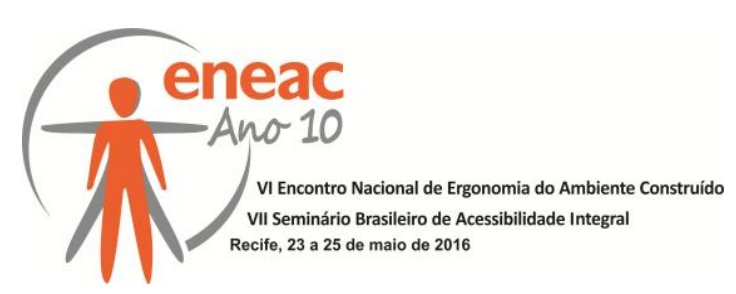

ZINNI, Juliana V. S; PUSSI F,lávia Ap.; COMIN, Alex T.; MOURA, Cibele de; FERRONATO, Evanilde; PRUDENCIO, Jessica; TESSARIM, Elaine. Esclerose Lateral Amiotrófica. Disponívelem:<http://www.wgate.com.br/conteudo/medicinaesaude/fisioterapia/neuro/escler ose_lat_amiotrofica.htm> Acesso: 09/02/2016. 